\title{
Purification of tubulin and microtubules from mouse brain
}

\author{
Xiangxiao $\mathrm{Li}^{1, *}$ \\ ${ }^{1}$ School of Pharmaceutical Science and Technology, Tianjin University, Tianjin, 300072, China
}

\begin{abstract}
Purified tubulin or microtubules are widely used for in vitro assays related to their function, such as activities of their modifying enzymes and motor protein activity. This paper gave a review for purification tubulin and microtubules (MTs) using two different methods. One method of purification MTs depended on polymerization and depolymerization. MTs were polymerized at $37{ }^{\circ} \mathrm{C}$ with taxol in the presence. Another method is to purify tubulin by affinity column chromatography. Stu2p, a kind of MAPs, is able to bind with C-terminal of tubulin. Recombinant Stu2p was purified from expressing bacteria. Then Stu2 $p$ was coupled with NHS-activated resins, which were used to purify tubulin from mouse brain. Tubulins purified in this way can also be polymerized at $37^{\circ} \mathrm{C}$.
\end{abstract}

\section{Introduction}

Microtubule (MT) is composed by the heterodimers of $\alpha$ and $\beta$-tubulin ${ }^{[1]}$. The tails of $\alpha$ - and $\beta$-tubulin from out surface of MTs support binding site for other protein, such as Microtubule Associate Proteins (MAPs) (Figure 1). They are an important part of the cytoskeleton and play an important role in maintaining cell morphology, cell division, signal transduction, and transport $[2,3]$. Under physiological conditions, microtubules have the kinetic properties of polymerization and depolymerization ${ }^{[4]}$. The structure of cells, the positioning and function of organelles depend on the stability of the microtubule structure. In vitro, MTs can polymerize at high temperature $\left(37{ }^{\circ} \mathrm{C}\right)$ and depolymerize at low temperature $\left(0-4{ }^{\circ} \mathrm{C}\right)$. The polymerized MTs can be further irreversibly stabilized by chemicals, such as taxol.

Purified tubulin or microtubules are widely used for in vitro assays related to their function, such as activities of their modifying enzymes and motor protein activity. In this research, I gave a review related to two methods for tubulin purification. One method is to use the MT polymerization ${ }^{[5]}$. Another method is to use the affinity chromatography ${ }^{[6]}$.

Members of the XMAP215/Dis1 family of microtubule-associated proteins (MAPs) are essential for promoting microtubule polymerization ${ }^{[7,8]}$. MAPs in this family contained several 250 residue repeats, called TOG domain ${ }^{[9]}$, which are thought to bind tubulin dimers and promote microtubule polymerization. Stu $2 p$ is a kind of lower eukaryotic homolog proteins of MAPs from Saccharomyces cerevisiae ${ }^{[10]}$. Widlund et al. designed a recombinant GST-stu2p to bind with tubulin [6]. GST-stu2p was firstly purified from Rosetta (DE3) using a GST affinity column. Then GST-stu $2 p$ protein was coupling with NHS-activated resins ${ }^{[11]}$. NHS-activated resin has NHS group, which can interact with free amino, such as the amino of N-terminus of GST-stu $2 p$ (Figure 2). The resins coupled with GST-stu2p are able to bind with tubulin.

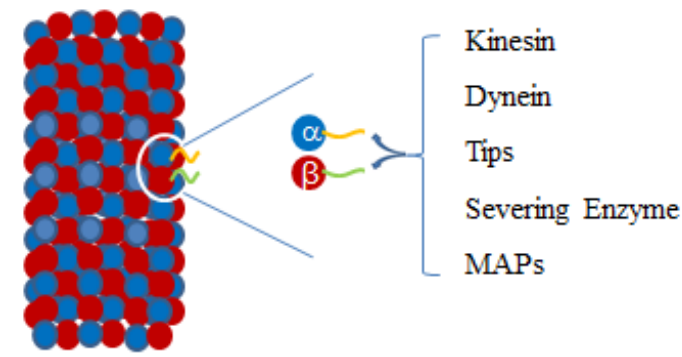

Figure 1 Schematic representation of the structure microtubules. Blue ball indicates $\alpha$-tubulin, red ball represents $\beta$-tubulin.

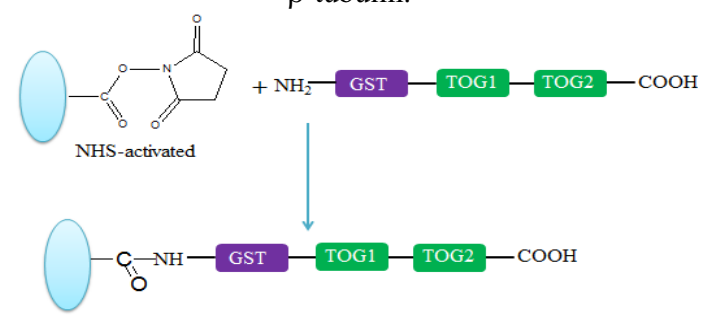

Figure 2 The principle of NHS-activated HP column coupling with stu2p.

\section{Method}

\subsection{Expression and purification of stu2p protein.}

pGEX6P1-stu2p was obtained from addgene (Catalog\#: 38314). This vector was fusion with a GST tag at the $\mathrm{N}$-terminus of the sequence. For protein expression, the plasmid was transformed into Rossetta ( $\lambda$ DE3) and

* Corresponding author: 760101559@,qq.com 
induced with $0.2 \mathrm{mM}$ isopropylthiogalactopyranoside (IPTG) at $16{ }^{\circ} \mathrm{C}$ for $18 \mathrm{~h}$. The harvested cells were resuspended in $2 \mathrm{x}$ PBS containing $25 \mu \mathrm{g} / \mathrm{mL}$ Lysozyme, $25 \mu \mathrm{g} / \mathrm{mL}$ DNase and $1 \mathrm{mM}$ PMSF. The cells were disrupted by sonication on ice using an ultrasonic processor (Ningbo scientz, China). The lysate was centrifuged at $40,000 \mathrm{xg}$ for $40 \mathrm{~min}$ at $4{ }^{\circ} \mathrm{C}$. The supernatant was loaded on $5 \mathrm{~mL}$ equilibrated GST-resins (Genscript, China) and incubated with resins at $4{ }^{\circ} \mathrm{C}$ for 2 h. After washing with $2 \mathrm{x}$ PBS containing $1 \mathrm{mM}$ dithiothreitol (DTT), $0.1 \%$ (v/v) tween 20 for 10 column volumes $(\mathrm{CV})$ and $2 \mathrm{x}$ PBS, $10 \mathrm{mM} \mathrm{MgCl}_{2}, 5 \mathrm{mM}$ ATP for $2 \mathrm{CV}$. The proteins were eluted with $5 \mathrm{mM}$ glutathione in 2x PBS containing $1 \mathrm{mM}$ DTT, $\mathrm{pH}$ 8.0. Monitored with SDS-PAGE followed by Coomassia Brilliant Blue (CBB) staining, the fractions containing the target protein were combined and dialyzed against $100 \mathrm{mM} \mathrm{NaHCO}, 100 \mathrm{mM} \mathrm{NaCl}, \mathrm{pH} 8.2$ with three changes. After concentrated using an ultrafiltration concentration tube (Millipore, USA), the protein concentration was determined using NanoDrop (Thermo Fisher Scientific, USA).

\subsection{Preparation of TOG column.}

Before coupling with NHS resin, the proteins were pooled to $100 \mathrm{mM} \mathrm{NaHCO}_{3}(\mathrm{pH}=8.2), 100 \mathrm{mM} \mathrm{NaCl}$ and $80 \mathrm{mM} \quad \mathrm{MgCl}_{2}$ (dialysis buffer). Firstly, NHS-activated fast-flow resins were packed in the column and then washed with $10 \mathrm{CV}$ ice-cold $1 \mathrm{mM} \mathrm{HCl}$. Next, GST-stu2p proteins were transferred to NHS-resin, and incubated at room temperature (RT) for $2 \mathrm{~h}$. The flow through was transferred to other tube following binding. The resins were washed with $0.5 \mathrm{M}$ ethanolamine and $0.5 \mathrm{M} \mathrm{NaCl}, \mathrm{pH}=8.3$ (block buffer) for $4 \mathrm{CV}$ and blocked with $6 \mathrm{CV}$ block buffer at RT for $1 \mathrm{~h}$. The block buffer was discarded and washed with $9 \mathrm{CV}$ 6x PBS, follow by $3 \mathrm{CV}$ storage buffer (1x PBS containing $50 \%$ glycerol). At last, this column was stored at $-20{ }^{\circ} \mathrm{C}$.

\subsection{Purification of tubulins from mouse brain using an affinity column.}

Tubulins were prepared from mouse brains using an affinity column. Firstly, the brain tissue is homogenized with a glass homogenizer (20 stocks) in 1.5 volumes of BRB80 buffer. Next the homogenate was collected by centrifugation at $40,000 \mathrm{xg}$ for $30 \mathrm{~min}$ at $4{ }^{\circ} \mathrm{C}$. Then the supernatant was transferred to column, incubated it at $4{ }^{\circ} \mathrm{C}$ for $2 \mathrm{~h}$. The flow through was transfer to other tube. The resins were washed with $1 \mathrm{x}$ BRB80 containing 10 $\mu \mathrm{M}$ GTP for (buffer A) 10CV, 1x BRB80 containing 100 $\mu \mathrm{M}$ GTP, $10 \mathrm{mM} \mathrm{MgCl}_{2}$, and $5 \mathrm{mM}$ ATP (buffer B) for 4 $\mathrm{CV}$. And resins were incubated with buffer $\mathrm{B}$ at $4{ }^{\circ} \mathrm{C}$ for $20 \mathrm{~min}$ in order to remove MAPs. Then resins were washed with $1 \mathrm{x}$ BRB80 containing $0.1 \%$ Tween 20 and $10 \%$ glycerol (buffer C) for $5 \mathrm{CV}$. At last, tubulins were eluted by $1 \mathrm{x}$ BRB 80 containing $10 \mu \mathrm{M}$ GTP and $500 \mathrm{mM}$ $\left(\mathrm{NH}_{4}\right)_{2} \mathrm{SO}_{4}$ and the concentration were monitored using Nanodrop. For desalting, target protein was desalted by
PD10 desalting column (GE healthcare, USA) and eluted with BRB80.

\subsection{Purification of MTs from mouse brain using taxol.}

The brain tissue is homogenized with a glass homogenizer ( 20 stocks) in 1.5 volumes of BRB80 buffer. The homogenate is centrifuged at $30,000 \mathrm{xg}$ in a TLA-150 rotor (Beckman) for $15 \mathrm{~min}$ at $2{ }^{\circ} \mathrm{C}$. The supernatant (S1) is recovered and centrifuged at 180,000 $\mathrm{xg}$ for $90 \mathrm{~min}$ in a TLA-150 rotor at $2{ }^{\circ} \mathrm{C}$. To the recovered supernatant (S2), taxol was added in a final concentration of $20 \mu \mathrm{M}$ and GTP to $1 \mathrm{mM}$. The solution is warmed at $37{ }^{\circ} \mathrm{C}$ for $30 \mathrm{~min}$, and transferred to a centrifuge tube. Equal volume of $10 \%$ sucrose containing $20 \mu \mathrm{M}$ taxol and $1 \mathrm{mM}$ GTP was cushioned in the bottom of mixture. The sample is centrifuged at $37^{\circ} \mathrm{C}$ at 30,000 xg for $30 \mathrm{~min}$. The pellet (MTs, designated as P3) was resuspended with BRB80.

\section{Results}

In order to prepare the affinity column for tubulin purification, recombinant GST-stu $2 p$ protein were purified from Rosetta (DE3) using GST resins according to Widlund ${ }^{[6]}$. The molecular weight of target protein is about $100 \mathrm{kDa}$. By comparing the supernatant (S) and flow through (FT), we can find that a large amount of protein was bound to GST-resin (Figure 3A). After monitored with SDS-PAGE, the eluate fractions majorly containing GST-Stu2p were combined and dialyzed against dialysis buffer at $4{ }^{\circ} \mathrm{C}$ overnight. These proteins were then coupled with NHS resin at RT for $2 \mathrm{~h}$. The coupling efficiency was monitored using SDS-PAGE followed by CBB staining. The results showed that most of GST-Stu2p was bound to NHS resin (Figure 3B).

We purified tubulin or microtubules (MTs) using two methods, one method is through affinity column (Figure 4A). Using prepared affinity column, tubulins were prepared from mouse brains using an affinity column. The molecular weight of tubulin is $55 \mathrm{kDa}$. Assessed with CBB-stained SDS-PAGE, tubulin appears as the major band after purification (Figure 4A). Another is taxol-assisted polymerization (Figure 4B). After polymerization, we got microtubules (P3) from mouse brain (Figure 4B). The purity of tubulin from first method is higher than that from second method. 


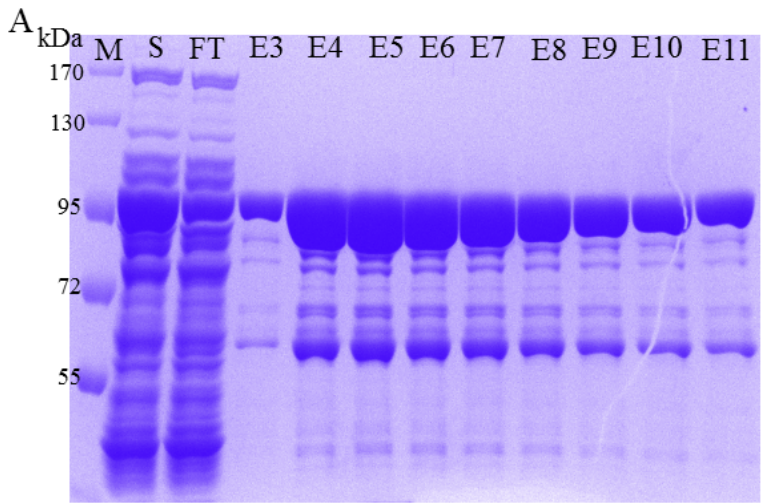

B

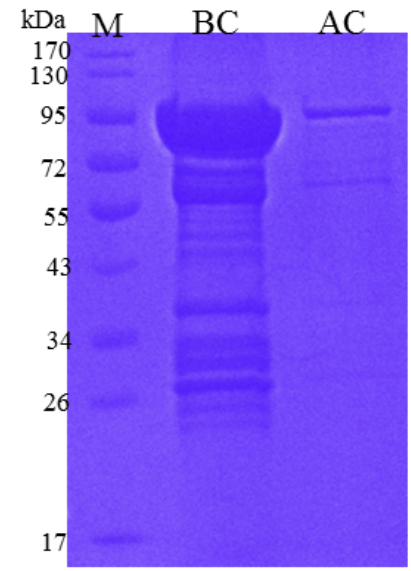

Figure 3 Purification of recombinant GST-stu2p protein for NHS-resin coupling. M means marker; (A) CBB-stained SDS/PAGE showed the proportion and purity of target proteins in soluble fraction (S), flow-through (FT), and elute (E) during purification of recombinant GST-Stu2p. (B) CBB-stained SDS/PAGE showed GST-Stup2 protein before coupling (BC) or after coupling (AC) with NHS-resins.

\section{Conclusion}

A review related to purification of tubulin and MTs was given in this paper. First method is to purify tubulin using an affinity column according to Widlund ${ }^{[6]}$. Firstly, Stu2p, a kind of MAPs, was expressed and purified from Rosetta competent cells. Then, stu2p was coupled with NHS-activated resins. The resins coupled with stu2p were able to binding with tubulin. I purified tubulin from mouse brain based on this affinity column. Another method is taxol-assisted polymerization. MTs were polymerized at $37{ }^{\circ} \mathrm{C}$ with taxol presence. After polymerization, we got microtubules from mouse brain. The purity of tubulin from first method is higher than it from second method. $1.2 \mathrm{mg}$ tubulin was prepared through the second method from 12 mouse brains.
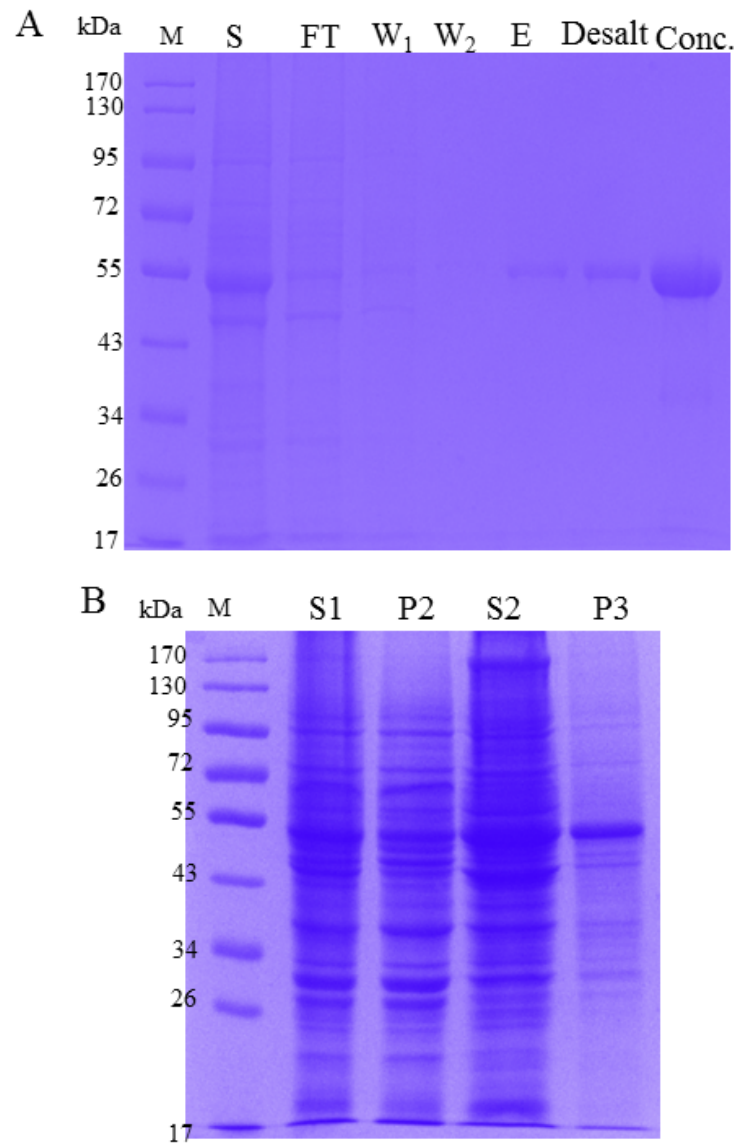

Figure 4 Purification of tubulin and MTs based on two different methods. M means marker; (A) CBB-stained SDS/PAGE showed the proportion and purity of tubulin in soluble fraction (S), flow-through (FT), wash (W) and elute (E) fraction. (B) Purification of MTs depended on polymerization and depolymerization. S1 is the brain lysate after homogenizer. S2 is the recovered supernatant after 1st run ultracentrifuge and P2 is the corresponding precipitation. $\mathrm{P} 3$ is the pellet obtained from $\mathrm{S} 2$ after addition of taxol.

\section{References}

1. Ku, S., Messaoudi, C., Guyomar, C., Kervrann, C., \& D Chrétien. (2020). Determination of microtubule lattice parameters from cryo-electron microscope images using tubule J. Bio-Protocol, 10, 3814.

2. Vemu, A., Garnham, C. P., Lee, D. Y., \& Rollmecak, A. (2015). Generation of differentially modified microtubules using in vitro enzymatic approaches. J. Methods Enzymol, 108(2), 451a-451a.

3. Souphron, J., Bodakuntla, S., Jijumon, A. S., Lakisic, G., Gautreau, A. M., \& Janke, C., et al. (2019). Purification of tubulin with controlled post-translational modifications by polymerization-depolymerization cycles. J. Nature Protocols.

4. Mirco, Castoldi,, Andrei, V., \& Popov. (2003). Purification of brain tubulin through two cycles of polymerization-depolymerization in a high-molarity buffer-sciencedirect. J. Protein Expression and Purification, 32(1), 83-88. 
5. Vallee R. B. (1986). Purification of brain microtubules and microtubule-associated protein 1 using taxol. J. Methods Enzymol, 134(4):104-115.

6. Widlund, P. O., M. Podolski, S. Reber, J. Alper, M. Storch, A. A. Hyman, J. Howard \& D. N. Drechsel (2012). One-step purification of assembly-competent tubulin from diverse eukaryotic sources. J. Molecular Biology of the Cell, 23(22), 4393-4401.

7. Al-Bassam, J. \& F Chang. (2011). Regulation of microtubule dynamics by tog-domain proteins xmap215/dis1 and clasp. J. Trends in Cell Biology, 21(10), 604-614.

8. Greenlee, M., A. Alonso, M. Rahman, N. Meednu,
K. Davis, V. Tabb, R. Cook and R. K. J. C. Miller. (2018). The tog protein stu2/xmap215 interacts covalently and non-covalently with sumo. J. Cytoskeleton.

9. Leano, J. B., \& Slep, K. C. (2018). Structures of TOG1 and TOG2 From the Human Microtubule Dynamics Regulator CLASP1.

10. Al-Bassam, J., Larsen, N. A., Hyman, A. A., \& Harrison, S. C. (2007). Crystal structure of a tog domain: conserved features of xmap215/dis1-family tog domains and implications for tubulin binding. J. Structure, 15(3), 355-362.

11. Healthcare G. E. (2006). HiTrap NHS-activated HP. 